trung bình là 89.828.747 \pm 11.497 .859$ VNĐ/QALY. Các yếu tố liên quan đến WTP/QALY bao gồm hệ số chất lượng sống theo thang đo EQ-5D-5L, hê số chất lượng sống theo thang đo VAS, nghề nghiệp, trình độ học vấn, mức thu nhập, bệnh kèm và giai đoạn bệnh. Như vậy, ngưỡng chi trả trên một năm sống có chất lượng đóng vai trò quan trọng trong việc đưa ra các quyết định về phần bổ nguồn lực $y$ tế.

\section{TÀI LIÊU THAM KHẢO}

1. Horak F., Doberer D., Eber E., et al. (2016), "Diagnosis and management of asthma-Statement on the 2015 GINA Guidelines", Wiener Klinische Wochenschrift, 128(15-16), pp.541-554.

2. Phan Quang Đoàn, Tôn Kim Long (2006), "Đô̂ lưu hành hen phế quản trong học sinh mốt số trường học ở Hà Nội và tình hình sử dụng Seretide dự phòng hen trong các đối tượng này", Y học thực hành, 547.

3. Vo T. Q., Nguyen H. M., Thai T. H., et al. (2019), "The economic burden attributable to asthmatic inpatients and outpatients in a military hospital, Vietnam: A retrospective 5-year analysis", JPMA. The Journal of the Pakistan Medical Association, 69(6), pp.S41-S48.
4. Mai V. Q., Sun S., Minh H. V., et al. (2020), "An EQ-5D-5L Value Set for Vietnam", Qual Life Res, 29(7), pp.1923-1933.

5. Hernandez G., Garin O., Dima A. L., et al. (2019), "EuroQol (EQ-5D-5L) Validity in Assessing the Quality of Life in Adults With Asthma: CrossSectional Study", J Med Internet Res, 21(1), pp.e10178.

6. Sullivan P. W., Kavati A., Ghushchyan V. H., et al. (2020), "Impact of allergies on health-related quality of life in patients with asthma", J Asthma, 57(11), pp.1263-1272.

7. Van Ha T., Van Hoang M., Vu M. Q., et al. (2020), "Willingness to pay for a quality-adjusted life year among advanced non-small cell lung cancer patients in Viet Nam, 2018", Medicine, 99(9), pp.e19379.

8. Hựy P. G. (2019), Phân tích ngưỡng chi trả trên mỗi năm sống có chất lượng cưa người bệnh $U$ lympho không Hodgkin tại một số bệnh viện Thành Phô Hồ Chí Minh.

9. Dunn R. M., Busse P. J., Wechsler M. E. (2018), "Asthma in the elderly and late-onset adult asthma", Allergy, 73(2), pp.284-294.

10. Costa E., Caetano R., Werneck G. L., et al. (2018), "Estimated cost of asthma in outpatient treatment: a real-world study", Rev Saude Publica, 52, pp.27.

\title{
KẾT QUẢ ĐIỀU TRI BÊNH TIÊU CHẢY CẤP Ở TRẺ TỪ 2 THÁNG ĐẾN 5 TUỔI TẠI BỆNH VIÊ̂N TRUNG ƯƠ'NG THÁI NGUYÊN
}

\section{TÓM TẮT}

Mục tiêu: Đánh giá kết quả điều trị bênh tiêu chảy cấp ở trẻ từ 2 tháng đến 5 tuổi tại Bệnh viện Trung ương Thái Nguyên. Đối tượng và phương pháp nghiên cứu: 202 bệnh nhi từ 2 tháng đến 5 tuổi mắc tiêu chảy cấp từ tháng 7/2020 đến tháng 6/2021, Bệnh viện Trung ương Thái Nguyên. Nghiên cứu mô tả cắt ngang. Kết quả: $100 \%$ bệnh nhi tiêu chảy cấp được điều trị bằng dung dịch ORS, thuốc kháng tiết đường ruột Hidrasec và Probiotics, 74,8\% được điều trị bằng dịch truyền. Sau $24 \mathrm{~h}$ và $48 \mathrm{~h}$ điêu trị, số trẻ tiêu chảy cấp có mất nước giảm từ $31,2 \%$ xuống $4,0 \%$ và $0,5 \%$. Sang ngày điều trị thứ 3 và thứ 5 , lần lượt có $13(6,4 \%)$ và $106(52,5 \%)$ trẻ đã không còn tiêu chảy. Tỷ lế bênh nhi có kết quả điều trị tốt là $98 \%$, thời gian điều trị trung bình là $5,0 \pm 2,4$ ngày, trong đó đa phần là $\leq 7$ ngày $(87,6 \%)$. Kết luận: Tất cả bệnh nhân đều được điểu trị theo phác đồ của Bộ Y tế, $98,0 \%$ bệnh nhân có kết quả điều trị tốt.

Tứ khoá: Tiêu chảy cấp, kết quả điều trị.

*Trường Đại học Y Dược Thái Nguyên

Chịu trách nhiệm chính: Phạm Việt Bách

Email: phamvietbachytn1994@gmail.com

Ngày nhận bài: 4.6.2021

Ngày phản biên khoa họ: 2.8.2021

Ngày duyệt bài: 12.8.2021

\section{Phạm Việt Bách*, Nguyễn Thành Trung*}

MMARY

RESULTS OF TREATMENT OF ACUTE

DIARRHEA IN CHILDREN FROM 2 MONTHS TO 5 YEARS OLD AT THAI NGUYEN NATIONAL HOSPITAL

Objectives: Assess the results of acute diarrhea in children from 2 months to 5 years old at Thai Nguyen National hospital. Subjects and methods: 202 patients from 2 months to 5 years old with acute diarrhea from July 2020 to June 2021 at Thai Nguyen National hospital. Descriptive cross-sectional study. Results: $100 \%$ patients were treated by ORS solution, Hidrasec and Probiotics, $74.8 \%$ were treated by infusion. After 24 and 48 hours of treatment, the number of children losing watery diarrhea decreased from $31.2 \%$ to $4.0 \%$ and 0.5 . After 3 and 5 days, 13 $(6.4 \%)$ and $106(52.5 \%)$ children went away. The rate of children with good results is $98 \%$, the average treatment time is $5.0 \pm 2.4$ days, of which the majority is $\leq 7$ days $(87.6 \%)$. Conclusion: All patients were treated according to the protocol of the Ministry of Health, $98,0 \%$ had good treatment results.

Keyword: acute diarrhea, result value.

\section{I. ĐẶT VẤN ĐỀ}

Tiêu chảy là một trong những nguyên nhân hàng đầu gây tỷ lệ mắc bệnh và tỷ lệ tử vong 
cao ở trẻ em, đăc biêt là các nước đang phát triển. Trong cuộc điều tra được thực hiện vào năm 2016 về gánh nặng của tiêu chảy từ 195 quốc gia, đây là nguyên nhân chính gây tử vong thứ 8 ở mọ lứa tuổi và chị trách nhiêm của 1.655.944 người chết. Ở trẻ em dưới 5 tuổi, tiêu chảy cấp là bệnh hay gặp nằm ở vị trí thứ 5 với khoảng 1,7 tỷ ca tiêu chảy xảy ra hàng năm và 446.000 trẻ em tử vong mối năm [8].

Báo cáo hội nghị đồng thuận khuyến cáo vê chẩn đoán và điều trị tiêu chảy cấp ở trẻ em năm 2014 và hướng dẫn chẩn đoán và điều trị bệnh tiêu chảy cấp ở trẻ em do Bộ $Y$ tế ban hành năm 2015 đã đưa ra phác đồ chi tiết trong chẩn đoán và điều trị bệnh. Mặc dù có phác đồ chung, tuy nhiên có sự khác nhau về kết quả điêu trị giữa các nghiên cứu. Tỷ lệ bệnh tiêu chảy cấp ở trẻ em vẫn còn cao nên việc đánh giá kết quả điều trị là rất quan trọng đối với thây thuốc nhi khoa. Kinh nghiệm trong điều trị giúp cho cán bộ y tế nhận định, điều trị sớm để rút ngắn thời gian điều trị, hạn chế tiêu chảy cấp mất nước và các biến chứng nặng của bệnh. Để đánh kết quả điều trị bênh tiêu chảy cấp theo phác đồ của Bô $Y$ tế tai bềnh viên Trung ương Thái Nguyên, chúng tôi tiến hành nghiên cứu đề tài này.

\section{II. ĐỐI TƯợNG VÀ PHƯƠNG PHÁP NGHIÊN CỨU}

2.1. Đối tượng nghiên cứu. Bệnh nhân từ 2 tháng đến 5 tuổi được chẩn đoán tiêu chảy cấp được điêu trị tại Trung tâm nhi khoa - Bệnh viện Trung ương Thái Nguyên từ tháng 7/2020 đển tháng $6 / 2021$.

\subsection{Tiêu chuẩn chọn bệnh}

\section{Tiêu chuẩn lựa chọn:}

+ Được chẩn đoán tiêu chảy cấp: Đi ngoài nhiều lần trong ngày ( $\geq 3$ lần trong 24 giờ) và phân lỏng hoặc tóe nước. Thời gian bắt đầu đợt tiêu chảy dưới 14 ngày [1].

+ Gia đình bệnh nhân đồng ý tham gia nghiên cứu.

+ Sử dụng phác đồ điều trị tiêu chảy cấp của Bộ Y tế năm 2015 [1].

Tiêu chuẩn loai trừ:

+ Tiêu chảy kéo dài (thời gian bắt đầu đợt tiêu chảy trên 14 ngày).

+ Xin ra viện khi bệnh chưa ổn định.

+ Chuyển viện: Các bệnh nhi đã điều trị mà các triệu chứng lâm sàng chưa thuyên giảm được chuyển viện lên tuyến trên điều trị tiếp.

2.3. Thiết kế nghiên cứu: Mô tả cắt ngang.

2.4. Cỡ mẫu và phương pháp chọn mẫu

- Cỡ mẫu: Áp dụng công thức tính cỡ mẫu ước tính một tỷ lệ trong quần thể nghiên cứu:

$$
\mathrm{n}=Z_{1-\alpha / 2}^{2} \cdot \frac{p \cdot(1-p)}{d^{2}}
$$

Tỷ lệ triệu chứng ước lượng từ nghiên cứu trước $\mathbf{p}=\mathbf{0 , 8 6 1}$ (Tỷ lệ trẻ mắc tiêu chảy có số ngày điều trị dưới 7 ngày là $86.1 \%$ [7]).

Cõ̃ mẫu tối thiểu là 184 bệnh nhân. Cỡ mẫu nghiên cứu thu được là 202 bệnh nhân.

\section{5. Định nghĩa các biến số}

- Kết quả điều trị

Tôt: + Khỏi: Các triệu chứng lâm sàng tốt hơn (đi ngoài ít hơn 3 lần/ngày, phân không còn toé nước, các triệu chứng cơ năng khỏi), được bác sĩ nhi khoa xác nhân là khỏi bênh và cho ra viên.

+ Đõ: Các triệu chứng lâm sàng đã giảm, đỡ, được bác sĩ nhi khoa xác nhận đã đõ̃ bệnh và cho ra viện, kê đơn thuốc về nhà uống và tiên lượng khỏi bênh.

Không tôt:

+ Bênh nhân tiêu chảy quá 14 ngày trở thành tiêu chảy kéo dài.

+ Tử vong.

2.6. Xử lý số liệu: Bằng phương pháp thống kê y học, sử dụng phần mềm SPSS 25,0 .

2.7. Đạo đức nghiên cứu. Được hội đồng đạo đức trong nghiên cứu y sinh học của bệnh viện Trung ương Thái Nguyên thông qua.

\section{KẾT QUẢ NGHIÊN CỨU}

3.1. Đăc điểm chung của nhóm bệnh nhân nghiên cứu

Bảng 1: Đặc điểm chung của đôî tượng nghiên cứu

\begin{tabular}{|c|c|c|c|}
\hline \multicolumn{2}{|c|}{ Đặc điểm } & $\begin{array}{c}\text { Số bệnh } \\
\text { nhân (n) }\end{array}$ & $\begin{array}{c}\text { Tỷ lệ } \\
(\%)\end{array}$ \\
\hline \multirow{3}{*}{ Tuổi } & $2-12$ tháng & 81 & 40,1 \\
\cline { 2 - 4 } & $13-24$ tháng & 84 & 41,6 \\
\cline { 2 - 4 } & $25-60$ tháng & 37 & 18,3 \\
\hline \multirow{2}{*}{ Giới } & Nam & 125 & 61,9 \\
\cline { 2 - 4 } & Nữ & 77 & 38,1 \\
\hline \multirow{2}{*}{$\begin{array}{c}\text { Địa } \\
\text { dư }\end{array}$} & Thành thị & 86 & 42,6 \\
\cline { 2 - 4 } & Nông thôn & 116 & 57,4 \\
\hline
\end{tabular}

Nhận xét: Hầu hết các bệnh nhân thuộc lứa tuổi nhỏ $2-24$ tháng $(81,7 \%)$, nam/nữ $=$ $125 / 77=1,6 / 1$. Bệnh gặp nhiêu hơn ở trẻ sống ở nông thôn $(57,4 \%)$.

3.2. Kết quả điêu trị

Bảng 2. Các thuốc được sử dụng trong điều trị tiêu chảy cấp

\begin{tabular}{|c|c|c|}
\hline Thuốc & Số bệnh nhân (n) & Tỷ lệ (\%) \\
\hline Oresol & 202 & 100 \\
\hline Hidrasec & 202 & 100 \\
\hline Probiotic & 202 & 100 \\
\hline Ringerlactat & 150 & 74,3 \\
\hline Kháng sinh & 32 & 15,8 \\
\hline
\end{tabular}


Nhận xét: 100\% được điều trị bằng dung dịch ORS, Hidrasec, Probiotic, 74,3\% bệnh nhân được điều trị bằng truyền dịch Ringerlactat, $15.8 \%$ được sử dụng kháng sinh.

Bảng 3. Tiến triển của mức độ mất nước trong quá trinh điều trị

\begin{tabular}{|c|c|c|c|c|c|c|}
\hline \multirow{2}{*}{$\begin{array}{l}\text { Thời điểm } \\
\text { Phác đồ }\end{array}$} & \multicolumn{2}{|c|}{$1-24 h(n=202)$} & \multicolumn{2}{|c|}{$25-48 h(n=202)$} & \multicolumn{2}{|c|}{$49-72 h(n=189)$} \\
\hline & Tân số & Tỷ lệ & Tân số & Tỷ lệ & Tân số & Tỷ lệ \\
\hline$A$ & 139 & 68,8 & 194 & 96,0 & 188 & 99,5 \\
\hline$B$ & 63 & 31,2 & 8 & 4,0 & 1 & 0,5 \\
\hline $\mathrm{C}$ & 0 & 0 & 0 & 0 & 0 & 0 \\
\hline
\end{tabular}

Nhận xét: Sau 1 ngày điều trị, số trẻ tiêu chảy cấp có mất nước điều trị theo phác đồ $\mathrm{B}$ giảm từ $31,2 \%$ xuống 4,0\%. Sau 2 ngày điêuu trị, có 13 trẻ đã được ra viện, 99,5\% trẻ bị tiêu chảy cấp không còn mất nước và được điều trị theo phác đồ $A$.

Bảng 4. Tiến triển cửa mức độ tiêu chảy trong quá trinh điều trị

\begin{tabular}{|c|c|c|c|c|c|c|}
\hline Thời điểm & Ngà̀y 1 & $=202$ & Ngày 3 & $=189)$ & Ngày & $=96)$ \\
\hline Số lân đỉ ngoài & Tần số & Tỷ lệ & Tần số & Tỷ lệ & Tân số & Tỷ lệ \\
\hline $3-5$ & 72 & 35,6 & 155 & 82,0 & 74 & 77,1 \\
\hline $6-9$ & 114 & 56,4 & 33 & 17,5 & 22 & 22,9 \\
\hline$\geq 10$ & 16 & 79 & 1 & 0,5 & 0 & 0 \\
\hline
\end{tabular}

Nhận xét: Ớ ngày thứ 3 và 5 điều trị, số lần đi ngoài trong ngày đều giảm, có lần lượt $13(6,4 \%)$ và $106(52,5 \%)$ trẻ đã khỏi bệnh.

Bảng 5. Thời gian điều trị tiêu chảy câp

\begin{tabular}{|c|c|c|}
\hline Số ngày tiêu chảy & $\begin{array}{c}\text { Số bệnh } \\
\text { nhân (n) }\end{array}$ & $\begin{array}{c}\text { Tỷ lệ } \\
\mathbf{( \% )}\end{array}$ \\
\hline$\leq 7$ ngày & 177 & 87,6 \\
\hline$>7$ ngày & 25 & 12,4 \\
\hline $\begin{array}{c}\text { Ngày điêu trị trung } \\
\text { bình } \pm \text { SD }\end{array}$ & \multicolumn{2}{|c|}{$5,0 \pm 2,4$} \\
\hline Tống & $\mathbf{2 0 2}$ & $\mathbf{1 0 0}$ \\
\hline
\end{tabular}

Nhận xét: Thời gian điêu trị trung bình bệnh tiêu chảy cấp ở trẻ em là $5,0 \pm 2,4$ ngày, trong đó hầu hết thời gian tiêu chảy $\leq 7$ ngày $(87,6 \%)$.

Bảng 6. Kết quả điều trị bệnh tiêu chảy cấp ở trẻ em

\begin{tabular}{|c|c|c|c|}
\hline \multicolumn{2}{|c|}{ Kết quả điêu trị } & $\begin{array}{c}\text { Số bệnh } \\
\text { nhân (n) }\end{array}$ & $\begin{array}{c}\text { Tỷ lệ } \\
(\mathbf{\%})\end{array}$ \\
\hline \multirow{2}{*}{ Tốt } & Khỏi & 185 & 91,6 \\
\cline { 2 - 4 } & Đõ & 13 & 6,4 \\
\hline \multirow{2}{*}{$\begin{array}{c}\text { Không } \\
\text { tốt }\end{array}$} & Tiêu chảy kéo dài & 4 & 2,0 \\
\cline { 2 - 4 } & Tứ vong & 0 & 0 \\
\hline \multicolumn{2}{|c|}{ Tống } & $\mathbf{2 0 2}$ & $\mathbf{1 0 0}$ \\
\hline
\end{tabular}

Nhận xét: Đa phần bệnh nhi bị tiêu chảy cấp có kết quả điêuu trị tốt (198/202; chiếm 98,0\%), chỉ 4 trường hợp chiếm 2,0\% chuyển sang tiêu chảy kéo dài.

\section{BÀN LUÂ̂N}

4.1. Các thuốc được sử dụng trong điêu trị tiêu chảy cấp. Kết quả ở bảng 2 cho thấy 100\% bệnh nhi được sử dụng dung dịch ORS đường uống trong bù nước và điện giải, $100 \%$ bệnh nhi được sử dụng thuốc kháng tiết đường ruột Hidrasec, $100 \%$ được sử dụng Probiotic để ổn định hệ vi sinh đường ruột, 15,8\% bệnh nhân được sử dụng kháng sinh để điều trị tiêu chảy cấp do vi khuẩn và tiêu chảy cấp có hội chứng ly. Kết quả của chúng tôi hoàn toàn phù hợp theo phác đồ hướng dẫn chẩn đoán và điều trị bệnh tiêu chảy cấp ở trẻ em do Bộ $Y$ tế ban hành năm 2015 và báo cáo hội nghị đồng thuận khuyến cáo về chẩn đoán và điều trị tiêu chảy cấp ở trẻ em [1].

Trong nghiên cứu của chúng tôi, $74,8 \%$ bệnh nhân được sử dụng dịch truyền Ringerlactat để điều trị bù nước và điện giải. Kết quả này thấp hơn so với nghiên cứu của Đỗ Phương Thảo, tỷ lệ bệnh nhân tiêu chảy cấp do rotavirus được truyền dịch chiếm tỷ lệ cao là $92,5 \%$ [5]. Tỷ lệ truyền dịch của chúng tôi cao hơn nghiên cứu của Vũ Thị Huyền với tỷ lệ bệnh nhân truyền dịch là $11,2 \%$ [4]. Lý do tý lệ truyền dịch của chúng tôi cao có thể là do có sự khác biệt trong nguyên nhân gây bệnh tiêu chảy cấp giữa các nghiên cứu gây nên mức độ mất nước khác nhau, do tỷ lệ trẻ có triệu chứng nôn và biếng ăn cao nên hiệu quả của bù nước và điện giải bằng đường uống trong ngày đầu nhập viện chưa thực sự mang lại hiệu quả như mong đợi, do cán bộ y tể đã điêu trị tích cực tình trạng mất nước bằng đường tĩnh mạch giúp tốc độ bù nước và điện giải cho trẻ nhanh hơn, đồng thời cũng mang lại tâm lý tích cực cho người chăm sóc trẻ.

4.2. Tiến triển của mức độ mất nước trong quá trình điều trị. Kết quả của chúng tôi ở bảng 3 cho thây trong 24 giờ đầu, có $68.8 \%$ trẻ tiêu chảy cấp không mất nước được đều trị theo phác đồ $A$ và $31.2 \%$ trẻ có mất nước được đều trị theo phác đồ $B$, không có trẻ nào mất nước nặng. Ngày thứ 2 điều trị, số trẻ tiêu chảy cấp khổng mất nước đã tăng lên $96,0 \%$, và số trẻ có mất nước giảm còn $4.0 \%$. Sang ngày thứ 3 điều trị, đã có 13 trẻ được ra viện, 99,5\% số 
trẻ còn lại không còn tình trạng mất nước, chỉ còn 1 trường hợp có mất nước và tiếp tục bù dịch theo phác đồ $\mathrm{B}$.

Kết quả của chúng tôi tương tự với các nghiên cứu khác: Nghiên cứu của Vũ Thị Huyên, trong ngày đâuu tiên nhập viện, có $46 \%$ trẻ không mất nước, $42 \%$ trẻ có mất nước và $12 \%$ trẻ mất nước nặng, đến ngày thứ 2 điều trị số trẻ không mất nước tăng lên $58 \%$, số trẻ có mất nước giảm còn $34 \%$ và số trẻ mất nước nặng còn $8 \%$, đến ngày thứ 3 điều trị, 1 trẻ đã được ra viện, $80 \%$ trẻ không còn mất nước, số trẻ có mất nước giảm còn $16 \%$, và chỉ còn 1 trường hợp mất nước nặng [4]. Nghiên cứu của Lương Cao Đồng, sau 1 ngày điều trị, số trẻ không mất nước là $66,7 \%$, có mất nước là $33,3 \%$, sau 2 ngày điều trị, số trẻ không mất nước tăng lên $88,9 \%$, có mất nước giảm còn $11,1 \%$ [2].

Như vậy, tình trạng mất nước được cải thiện rõ rệt sau khi điêu trị tiêu chảy cấp theo đúng phác đồ tại bệnh viện. Sau 2 ngày điều trị, hầu hết các bệnh nhi (99.5\%) không còn tình trạng mất nước và được chuyển sang điều trị theo phác đồ $A$, tuy nhiên do trẻ vẫn còn tình trạng tiêu chảy, tâm lý muốn điều trị khỏi bệnh hoàn toàn của cha mẹ trẻ và để đảm bảo trẻ được điều trị đúng và đủ theo phác đồ nên phần lớn trẻ vẫn tiếp tục được điều trị tại bệnh viện.

4.3. Tiến triển của mức độ tiêu chảy trong quá trình điêu trị. Theo Vũ Thị Huyền, trong ngày đầu tiên vào viện, số lần đi ngoài trung bình là 5,21 $\pm 2,18$ lần/24giờ, sang 24h điêu trị tiếp theo số lần đi ngoài giảm còn $3,61 \pm$ 0,87 lần/24h ở nhóm $6-11$ tháng, 3,52 $\pm 0,86$ lần/24h ở nhóm trẻ $12-24$ tháng, 3,4 $\pm 1,28$ lần ở lứa tuổi 24 - 36 tháng, sang đến ngày thứ 3 điều trị giảm còn $2,40 \pm 0,70$ lần/24giờ ở lứa tuổi 6-11 tháng, 2,62 \pm 0,77 lần/24giờ ở lứa tuổi 12 - 23 tháng và $2,43 \pm 1,24$ lần/24giờ ở lứa tuổi 24-36 tháng [4]. Nghiên cứu của Lương Cao Đồng cho kết quả: trước điều trị, số trẻ đi ngoài 3-5 lần chiếm 7,4\%, từ 6-9 lần là 70,4\%, $\geq 10$ lần là $22,2 \%$. Sang ngày thứ 2 điều trị, đã có $11,1 \%$ trẻ cầm tiêu chảy, $66,7 \%$ trẻ đi ngoài $1-5$ lần/ngày, 22,2\% trẻ đi ngoài từ 6-9 lần/ngày và không còn trẻ nào đi quá 10 lần. Sang ngày thứ 3 điều trị, số trẻ không còn tiêu chảy là $33,3 \%$, $63,0 \%$ trẻ đi ngoài 1-5 lần/ngày và chỉ còn $3,7 \%$ trẻ đi ngoài 6-9 lần/ngày [2].

Trong nghiên cứu của chúng tôi, trong ngày đầu tiên nhập viện có $35.6 \%$ trẻ đi ngoài từ 3-5 lần/ngày, 56,4\% trẻ đi ngoài 6-9 lần/ngày và $7,9 \%$ trẻ đi ngoài $\geq 10$ lần/ngày. Đến ngày điều trị thứ 3, đã có 13 trẻ khỏi bệnh và được ra viện,
$82,0 \%$ số trẻ còn lại đi ngoài 3-5 lân/ngày, $17,5 \%$ trẻ đi ngoài $6-9$ lần/ngày và chỉ còn 1 trường hợp đi ngoài $\geq 10$ lần/ngày. Đến ngày điều trị thứ 5,106 trẻ đã được ra viện, $77,1 \%$ số trẻ còn lại đi ngoài 3-5 lần/ngày, 22,9\% đi ngoài 6-9 lần/ngày và không còn trường hợp nào đi ngoài quá 10 lần/ngày. Kết quả của chúng tôi phù hợp với kết quả của các tác giả trên, đến ngày điêu trị thứ 3 và thứ 5 , số lần đi ngoài trong ngày đều giảm rõ rệt. Điều này cho thấy đa phần bệnh nhân đều đáp ứng tốt với các thuốc trong phác đồ điều trị bệnh tiêu chảy cấp.

4.4. Kết quả điêuu trị bệnh tiêu chảy cấp ở trẻ em. Kết quả ở bảng 6 cho thấy phần lớn bệnh nhi mắc tiêu chảy cấp có kết quả điều trị tốt chiếm $98 \%$, chỉ có 4 trường hợp $(2,0 \%)$ tiêu chảy kéo dài, không có trường hợp nào chuyển viện hay tử vong. Đa phần bệnh nhi có thời gian điều trị $\leq 7$ ngày $(87,6 \%)$, thời gian điều trị trung bình bệnh tiêu chảy cấp ở trẻ em là 5,0 \pm 2,4 ngày (bảng 5).

Kết quả điều trị của chúng tôi tương đồng với một số nghiên cứu khác: Nghiên cứu của Lương Cao Đồng tại khoa nhi bệnh viện quân y 103 năm 2015 trên 57 bệnh nhi tiêu chảy cấp, tỷ lệ điêu trị khỏi bệnh dưới 7 ngày là $100 \%$ [2]. Nghiên cứu của tác giả Nguyển Thành Trung là $86,14 \%$ trẻ tiêu chảy dưới 7 ngày, trung bình thời gian tiêu chảy là $5 \pm 2,04$ ngày [7]. Nghiên cứu của Lê Tấn Giàu tại khoa nhi bệnh viện Đa khoa trung tâm Tiền Giang năm 2017 trên 123 trẻ tiêu chảy cấp dưới 5 tuổi cho thây $100 \%$ bệnh nhân điêu trị phục hồi hoàn toàn, thời gian điêu trị trung bình là 4,6 \pm 2 ngày [3]. Nghiên cứu của Phạm Võ Phương Thảo năm 2021, đa phần bệnh nhi mắc tiêu chảy có thời gian điều trị dưới 7 ngày chiếm $67,6 \%$, điều trị $\geq 7$ ngày là $32,4 \%$, thời gian điều trị trung bình là 5,62 \pm 2,58 ngày [6].

Kết quả trên cho thấy hiệu quả cao của phác đồ điều trị bệnh tiêu chảy cấp của WHO và Bộ $Y$ tế, cũng như khẳng định Oresol, Hidrasec, Probiotics vẫn là thuốc đâu tay trong điều trị tiêu chảy cấp ở trẻ em.

\section{KẾT LUÂ̂N}

Tất cả bệnh nhi tiêu chảy cấp được điều trị theo phác đồ Bộ Y tế bằng dung dịch ORS, thuốc kháng tiết đường ruột Hidrasec và Probiotic, $74,8 \%$ được điều trị bằng dịch truyền ringerlactat.

$98,0 \%$ bệnh nhân có kết quả đều trị tốt, $87,6 \%$ bệnh nhi có thời gian điêu trị $\leq 7$ ngày, thời gian điều trị trung bình bệnh tiêu chảy cấp ở trẻ em là 5,0 $\pm 2,4$ ngày. 
TÀI LIỆU THAM KHẢO

1. Bộ Y tế (2015), "Tiêu chảy cấp", Hướng dẫn chẩn đoán và điều trị một số bệnh thường gặp ở trẻ em, Hà Nội, Nhà xuất bản y học, tr. 316-324.

2. Lương Cao Đồng (2015), "Đánh giá hiệu quả điêuu trị tiêu chảy cấp do Rotavirus bằng Racecadotril ở bệnh nhi dưới 6 tuổi điều trị tại khoa Nhi, Bênh viện quân y 103 ", Tạp chí Y'Dược học quần sự. 5, tr. 105-111.

3. Lê Tấn Giàu, Trương Công Đây và Ta Văn Trâm (2017), "Đặc điểm bệnh tiêu chảy cẩp điều trị nội trú tại khoa Nhi Bệnh viện đa khoa trung tầm Tiên Giang từ 01/8/1016 đến 31/10/2016 ", Tạp chí y học thành phố Hồ Chí Minh. 21(6), tr. 1-4.

4. Vũ̃ Thị Huyền (2010), Đánh giá kết quả điều trị hỗ trợ bệnh tiêu chảy cấp bằng thuốc kháng tiết đường ruột hidrasec tại khoa nhi - bệnh viện đa khoa Trung ương Thái Nguyên, Luận vằn thạc sỹ y học, Trường đại học Y Dược Thái Nguyên.
5. Đỗ Phương Thảo (2015), Đặc điểm dịch tễ học lâm sàng bệnh tiêu chảy cấp do rotavirus ở trẻ dưới 5 tuổi tai bệnh viện Nhi Trung Ương, Luận văn bác sỹ nội trú, Trường đại học Y Hà Nội.

6. Phạ Võ Phướng Thảo (2021), "Nghiên cứu đă̆c điểm lâm sàng và cận lâm sàng bệnh tiêu chảy cấp ở trẻ từ 2 tháng đến 5 tuối tại Bệnh viện Trung ương Huế", Tap chí Y Dược học - Trường Đại học Y Dược Huế. Số 1(11), tr. 24-29.

7. Nguyê̂n Thành Trung (2015), Nghiên cứu đăc điểm lâm sàng, cận lâm sàng và một số tác nhẩn gây bênh tiêu chảy cấp ở trẻ em, Luẩn văn Thac sỹ của Bác sĩ nội trú, Trường Đại học Y Dược Huế.

8. Nshimiyimana, Ladislas Onyambu, Peris Monchari Rutayisire et al (2020), "Diarrhoeal Diseases in Children Under Five Years Exhibited Space-Time Disparities and Priority Areas for Control Interventions in Rwanda 08 May 2020", PREPRINT (Version 1) available at Research Square.

\title{
ĐẶC ĐIỂM HÌNH ẢNH THỦNG TẠG RỖNG TRÊN X QUANG, CẮT LỚP VI TÍNH VÀ SIÊU ÂM Ổ BỰG
}

\author{
Nguyễn Văn Thắng*, Nguyễn Thành Luân*, Đinh Việt Khôi*
}

\section{TÓM TẮT}

Mục tiêu: Mô tả một số đặc điểm hình ảnh bênh lý thủng tạng rỗng trên x quang, cắt lớp vi tính và siêu âm ổ bụng. Đối tượng và phương pháp: Nghiên cứu mô tả cắt ngang 31 bệnh nhân đến khám cấp cứu bụng và được chẩn đoán xác định là thủng tạng rỗng tại bênh viên Hữu Nghi Việt Đức từ 11/2020 đến 05/2021. Kết quả: Tống cộng $31 \mathrm{BN}$, bao gồm 23 nam $(74.2 \%)$ và 8 nữ $(25.8 \%)$. Tuổi mắc bênh trung bình $53,77 \pm 21,9$. Thủng tá tràng chiếm tỷ lệ cao nhất $(32.25 \%)$, tiếp đến là da dày và ruôt non $(25.8 \%)$. Trên x quang bụng cấp cứu, dẫu hiệu dịch tự do ổ bung chiếm $73.3 \%$, dấu hiếu liềm hơi dưới hoành chiếm $23.3 \%$. Trên cắt lớp vi tính ổ bụng, dấu hiệu khí ngoài ống tiêu hóa chiếm $74.2 \%$, thâm nhiễm mỡ mạc treo chiếm $71 \%$. Trên siêu âm ổ bụng, dấu hiệu "rèm cửa" chỉ thây được ở 3 trường hợp (chiếm 13\%).

Tư khóa: Thủng tạng rông, $X$ quang, Cắt lớp vi tính, Siêu âm ổ bụng

\section{SUMMARY \\ IMAGING CHARACTERISTICS ON KUB X- RAY, CT AND ABDOMINAL SONOGRAPH IN PNEUMOPERITONEUM}

Purpose: To describe imaging characteristics on KUB x-ray, abdominal CT and abdominal sonograph in pneumoperitoneum. Material and method: Descriptive cross-sectional study on 31 patients who

*Trường Đại học Kỹ thuật Y tế Hải Dương

Chịu trách nhiệm chính: Nguyễn Văn Thắng

Email: nguyenvanthang@hmtu.edu.vn

Ngày nhận bài: 7.6.2021

Ngày phản biên khoa hoc: 4.8.2021

Ngày duyệt bài: 13.8.2021 admitted to Viet Duc hospital for acute pain in their abdomen and diagnosed pneumoperitoneum from November 2020 to May 2021. Result: A total of 31 patients included 23(74.2\%) males and $8(25.8 \%)$ females: mean age is $53,77 \pm 21,9$. Doudenal perforation was showed hightest $(32.3 \%)$, stomach and intestinal perforation (25.8\%). On KUB x-ray, free peritoneal effusion was showed $73.3 \%$, subdiaphragmatic free gas was showed $23.3 \%$. On abdominal computer tomography, extragastrointestinal gas was showed $73.3 \%$. On abdominal sonograph, peritoneal stripe sign was showed

Keywords: Pneumoperitoneum, KUB x-ray, abdominal sonographer

\section{I. ĐẶT VẤN ĐỀ}

Thủng tạng rỗng là một trong những cấp cứu bụng ngoại khoa thường gặp nhất, nguyên nhân có thể là một trong những biến chứng của ổ loét dạ dày-tá tràng, viêm ruột cấp hay các biến chứng của phẫu thuật, nội soi. Các phương pháp chẩn đoán hình ảnh như siêu âm, chụp $x$ quang và cắt lớp vi tính ổ bụng cho những hình ảnh có giá trị đặc hiệu và tin cậy giúp chẩn đoán và xử trí kịp thời. Chẩn đoán bằng $x$ quang đem lại hiệu quả rất cao với việc phát hiện rõ liềm hơi dưới cơ hoành [1]. Tuy nhiên, khi lượng khí rất bé, chỉ vài $\mathrm{mm}$ thì trên màn ảnh $x$ quang sẽ khó phát hiện được. Những năm gần đây, vaii trò của siêu âm trong chẩn đoán thủng tạng rỗng được nhiều nhà chẩn đoán hình ảnh báo cáo là phương pháp thăm khám có giá trị tuy nhiên phụ thuộc nhiều vào người làm siêu âm. Dấu hiệu 